
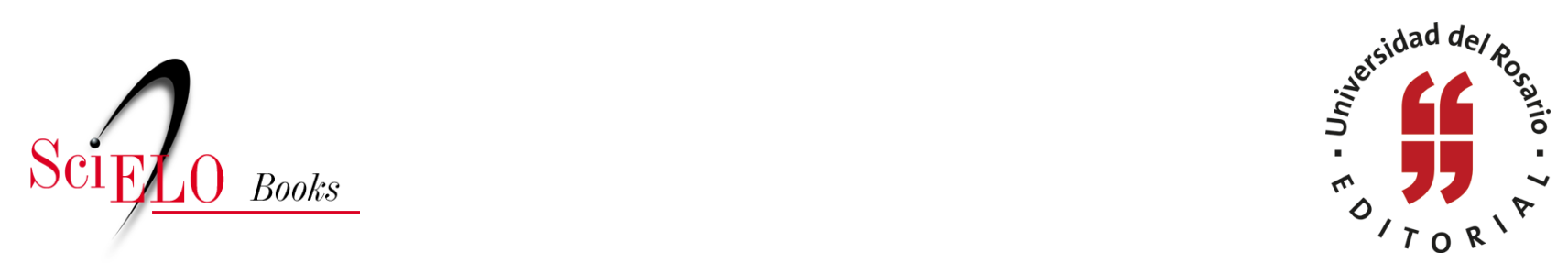

\title{
Capítulo 3 \\ La caridad de la Iglesia y la filantropía del Estado
}

\author{
Sindy Paola Veloza Morales
}

VELOZA MORALES, S.P. La caridad de la Iglesia y la filantropía del Estado. In: La política entre nubes de incienso. La participación política de las asociaciones católicas laicas bogotanas (1863-1885) [online]. Bogotá: Editorial Universidad del Rosario, 2014, pp. 75-94. Opera prima collection. ISBN: 978-958-738-504-5. https://doi.org/10.7476/9789587385045.0004.

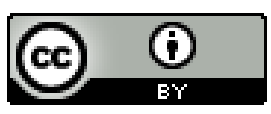

All the contents of this work, except where otherwise noted, is licensed under a Creative Commons Attribution 4.0 International license.

Todo o conteúdo deste trabalho, exceto quando houver ressalva, é publicado sob a licença Creative Commons Atribição 4.0.

Todo el contenido de esta obra, excepto donde se indique lo contrario, está bajo licencia de la licencia Creative Commons Reconocimento 4.0 . 


\section{Capítulo 3 \\ La caridad de la Iglesia y la filantropía del Estado}

Elprincipal objetivo de los hijos de San Vicente i las hermanas de la caridad es el de aliviar a los necesitados, volver al buen camino a la mujer extraviada, recoger al buérfano $i$ al mendigo, en fin, continuar esa serie de milagros de bondad que solo el cristianismo ba sido fecundo, consolando todo dolor, i secando toda lagrima. ${ }^{1}$

\section{Las constantes guerras civiles ${ }^{2}$ y los cambios en las políticas fiscales generaron una serie de transformaciones sociales y económicas en el país: algunos comerciantes fueron a la}

$1 \quad L a$ Caridad, 1865. "Discurso", 5 de enero.

2 En el período 1863-1885 el país se ve afectado por diferentes guerras civiles, tres de ellas de gran trascendencia: la primera, desarrollada entre 1860 y 1862, da inicio a los gobiernos liberales y deja como consecuencias una considerable pérdida económica, a casi toda la población en situación de pobreza y un malestar social generalizado. La segunda guerra, comprendida entre 1876 y 1877 , será definida como un conflicto político-religioso desarrollado en torno a la reforma educativa de 1870. La tercera, desde1884 hasta 1885, pone fin al gobierno liberal y marca el inicio a la Regeneración. Esta confrontación bélica deja a los radicales liberales fuera del poder. Sin embargo, los tres enfrentamientos descritos no fueron los únicos que se presentaron durante el período: existían amenazas de conflicto paralelas gracias a la presencia de guerrillas en Cundinamarca y disputas partidistas. Estas condiciones impidieron que en Bogotá se diera una duradera estabilidad económica, política y social, lo que agravó, de una manera u otra, las condiciones de vida de la población. Véase: Ortiz, Fusiles y plegarias. 
quiebra con las medidas poco proteccionistas del Gobierno; muchas familias, al ver a los padres o hijos marcharse a la guerra, se quedaron sin el sustento necesario para vivir; otros tuvieron que desplazarse a las ciudades en busca de mejores oportunidades, tratando de alejarse de los contantes conflictos en el campo.

Si a esto agregamos la falta de políticas sociales y la ineficacia de las ya existentes, producto de la inestabilidad institucional, tenemos como resultado un gobierno incapaz de crear y consolidar mecanismos de control y atención a la población necesitada; al tiempo que se da un aumento en los índices de pobreza y mendicidad en la ciudad y el país. ${ }^{3}$

En Bogotá, como en el resto del país, la presencia de pobres y mendigos generó una gran preocupación, por lo que tanto el Gobierno como los sectores privados procuraron desarrollar medidas para atender y controlar a esta población. ${ }^{4}$ Así, las elites desarrollaron diferentes acciones para atender la pobreza con el fin, por un lado, de seguir las enseñanzas cristianas o humanistas de ayuda al prójimo y, por otro, de evitar o controlar algún posible levantamiento. El antecedente del golpe militar de José María Melo apoyado por los artesanos había provocado el afán de prevenir cualquier acción masiva del pueblo, de ahí que las élites es-

3 En el texto de Miguel Samper, La miseria en Bogotá, de 1867, se puede encontrar una detallada descripción de la pobreza en la ciudad. Por su parte, Germán Mejía relata gran presencia de mendigos y pobres para la época. Mejía, Los años de cambio, 278.

$4 \quad$ Castro, Caridad y beneficencia, 17. 
tuvieran preocupadas por el aumento de una población sin recursos, numerosa y activa.

Frente a la necesidad de controlar y atender a este sector se promovieron diferentes estrategias, dos de las cuales fueron: la institucional o estatal, y la privada católica, que funcionaron paralelamente, apoyándose y enfrentándose entre sí.

El gobierno liberal intentó recuperar el control sobre los centros de beneficencia antes pertenecientes a la Iglesia, a través de la política de desamortización de bienes de manos muertas. Y aunque con estas medidas la Iglesia fue desplazada de los hospitales y centros de atención, las condiciones económicas, la falta de personal y el incremento de pobres, hicieron que el Gobierno utilizara una administración mixta de los centros de asistencia: mientras los establecimientos eran dirigidos y estaban financiados por el Estado, la Iglesia y las sociedades católicas recolectaban fondos y ayudaban en la atención de enfermos o necesitados en los hospitales y asilos. ${ }^{5}$

Después de 1870 la ayuda institucional empieza a organizarse y a formalizarse con la creación de nuevos establecimientos en las principales ciudades. Para el caso de Cundinamarca, en 1869 se crea la Junta General de Beneficencia con el fin de coordinar todas las obras de caridad que se realizaban en el estado. ${ }^{6}$ Si bien la junta se distinguió por su

5 Beatriz Castro, "Los inicios de la asistencia social en Colombia", Revista CS, n. ${ }^{\circ} 1$ (2007), 157.

6 Castro, Caridad y beneficencia, 116. 
carácter laico y buena organización, gran parte del trabajo de los establecimientos tuvo que ser realizado en compañía de la Iglesia y de organizaciones católicas.

A pesar de los intentos realizados, los establecimientos estatales no cubrían las necesidades de la población, de ahí que se les permitiera a las asociaciones privadas crear establecimientos de ayuda benéfica. Esto permitió que el trabajo caritativo desplegado desde las sociedades católicas y la Iglesia se desarrollara de manera simultánea con las políticas sociales del Estado. Es por esto por lo que podemos encontrar un diálogo constante entre ambas partes en el momento de decidir, por ejemplo, quién debía dirigir ciertos centros de atención, cuáles eran las necesidades más apremiantes y cuáles deberían ser los fondos destinados a la asistencia. La atención a la población necesitada fue un espacio principal de encuentro entre las sociedades católicas y el Estado.

\section{La caridad cristina}

Una de las actividades más importantes de las sociedades laicas de la segunda mitad del siglo xix fueron las labores de caridad. Si bien las políticas de desamortización de bienes de manos muertas y el proyecto secularizarte disminuyeron el campo de acción de la Iglesia, no lograron hacer que la participación del clero y las asociaciones católicas en la atención de la población en condiciones de pobreza fuese menos relevante.

Como el problema de la pobreza logró ocupar las agendas estatales y privadas, las labores de caridad, beneficencia y atención, eran desarrolladas por una amplia gama de per- 
sonas, ya fueran liberales, conservadores, mujeres o artesanos. Así, mientras se formulaban soluciones de lado y lado, cada sector fue estableciendo diferencias en la forma como se atendía a la población. En este sentido, las sociedades establecieron una clara diferencia entre el proceso de atención institucional, promovido por el Estado, y su propuesta de caridad cristiana. Mientras la caridad se promovió como un deber religioso, un compromiso moral en busca del progreso social y un medio para controlar las amenazas sociales, la filantropía o beneficencia, ${ }^{8}$ desarrollada por los sectores liberales y el Estado, fue vista como un proceso frío e insensible. En palabras de José María Vergara:

¿He de decirle que en lugar de ese santo fuego que él conoció bajo el nombre de caridad, se usa hoy un frío sentimiento que se llama filantropía, y que consiste en no buscar al pobre por amor a Dios, sino en alejarlo por amor a sí mismo??

Así, a los ojos de los miembros de las sociedades, mientras el Estado propone la creación de centros de atención,

7 Castro, Caridad y beneficencia, 17.

8 Beatriz Castro afirma que en vez de filantropía el término usado por los católicos fue el de beneficencia, por cuanto el concepto de filantropía no fue plenamente aceptado en Colombia y su uso hacía referencia solo a aquellas personas que se limitaban en dar dinero. Castro, Caridad y beneficencia, 22. Sin embargo, en los artículos de prensa que encontramos al respecto vimos con mayor constancia el concepto de filantropía, por lo que lo utilizaremos en la presente investigación. 7 de julio.

La Caridad, 1865. "Discurso en de la Sociedad de San Vicente de Paúl”, 
que de manera temporal e igualitaria atienden a personas sin recursos o que se encuentran enfermas ofreciéndoles solo ayudas materiales, como alojamiento, comida y cuidados médicos; la Iglesia y las sociedades católicas promovían una atención cristiana que, además de suministrar las condiciones básicas de vida y bienestar, ofrecía una cura para el alma y los vicios de los pobres.

Si bien en la práctica las formas de ayuda y la concepción de la pobreza no variaron mucho entre el gobierno y los fieles caritativos, pues ambas partes fundaron el mismo tipo de establecimientos y vieron en los pobres un sector afectado por las condiciones sociales, con deficiencias morales y educativas, ${ }^{10}$ la visión de caridad frente a la de filantropíabeneficencia, significó una fuerte tensión entre el Estado y las sociedades católicas, al tiempo que les brindó a las segundas un discurso diferenciador en su acercamiento a otros sectores de la población, ya que, según estas, mientras el Gobierno quería simplemente controlar y atender superficialmente (filantropía) a los necesitados, los miembros de las sociedades pretendían una regeneración moral, la salvación del alma, un acercamiento real a las necesidades de los pobres.

La lógica de una atención caritativa contrapuesta a una medida filantrópica del Gobierno fue una herramienta utilizada constantemente por las sociedades para atacar el proyecto liberal, el cual fue acusado de no preocuparse realmente por las condiciones de vida del pueblo. De ahí que las sociedades católicas vieran la posibilidad de utilizar su labor

10 Castro, Caridad y beneficencia, 65-67. 
de caridad como un medio para atacar las políticas liberales y defender el papel social de la Iglesia y la religión:

Señor [funcionario del gobierno encargado]: esos enfermos que agonizan ahí sobre la dura tabla, careciendo de alimentos, de medicinas y de abrigo son colombianos, hermanos nuestros, cristianos! Han llegado allí en la persuasión de que iban a recibir servicios, no gratuitos sino debidos, como quien cobra una deuda sagrada; de que el pan que se les debía dar allí era un legado de hombres de otra generación que se despojaron de lo suyo en favor de los pobres. ${ }^{11}$

Acusaciones constantes de mal funcionamiento, corrupción, mala atención de los enfermos y los necesitados, y poca preocupación por la sanación espiritual, fueron varias de las críticas que recibió el Gobierno por parte de las elites ultramontanas, las cuales afirmaban que la Iglesia desarrollaba mejores programas de caridad.

Las sociedades católicas procuraron desarrollar, paralelamente al trabajo caritativo, el descrédito de las políticas sociales de los liberales, con el fin de dar mayor legitimidad a su posición en la ciudad: eran ellas las que atendían a los pobres, cubrían deficiencias estatales y lo hacía todo desde el espíritu desinteresado del cristianismo. Si a esto sumamos que el Estado tuvo que recurrir a clérigos, órdenes religiosas y voluntarios de las sociedades católicas para cumplir con

11 La Caridad, 1868. "Visita a un hospital”, 15 de julio. 
la atención en colegios y establecimientos de beneficencia, ${ }^{12}$ lo que existía eran elementos suficientes que justificaban la presencia de las sociedades católicas en Bogotá.

Entre las labores de caridad que desarrollaron las sociedades católicas están la que se describen a continuación.

\section{Hospitales, asilos, orfanatos y visitas domiciliarias}

De las sociedades más activas en este campo encontramos a la Sociedad de San Vicente, que en 1860 fundó un hospital en Bogotá. Este establecimiento funcionó con la ayuda de la sociedad de Beneficencia, la cual estaba conformada por mujeres, encargadas de la obtención de fondos, ropa y alimentos. El hospital estuvo abierto hasta 1872, cuando cerró por falta de presupuesto. Durante su funcionamiento, atendió a 1255 personas de la capital. ${ }^{13}$ Luego del cierre, el edificio, ubicado en Las Aguas, fue convertido en una escuela para niños y niñas. Así, para 1870 el único hospital en funcionamiento en Bogotá era el San Juan de Dios, el cual funcionaba bajo la dirección de la Junta General de Beneficencia con ayuda de las sociedades del Sagrado Corazón de Jesús y las Hijas de María.

También existía la casa refugio, el hospicio para los huérfanos y los niños pobres, y dos asilos para indigentes, uno para hombres y otro para mujeres. ${ }^{14}$ El asilo de mujeres

12 Eugenio Gutiérrez, La politica instruccionista de los radicales: intento fallido de modernización de Colombia en el siglo XIX (1870-1878) (Neiva: Fondo de Autores Huilenses, 2000), 47-48.

13 Castro, Caridad y beneficencia, 123.

14 Castro, Caridad y beneficencia, 130. 
estaba bajo la dirección de la sociedad del Sagrado Corazón de Jesús, la cual se encargó de mejorar las instalaciones, así como de administrar el establecimiento.

Por su parte, la Sociedad de Niños Desamparados fundó, a principios de la década de 1880, el asilo de niños desamparados, ${ }^{15}$ que funcionó durante corto tiempo. Este establecimiento llama la atención por estar dirigido por varias personalidades del Partido Liberal, entre otros por Manuel Ancízar y Juan Obregón, hecho que nos muestra que el tema de la beneficencia y la atención de los necesitados, así como la creación de sociedades caritativas, no correspondió de manera exclusiva a las elites ultramontanas, sino que se planteó como un asunto concerniente a todo aquel que se considerara un verdadero cristiano y un buen ciudadano.

Ahora bien, en la lógica de entender caridad como un deber religioso, los hospitales no funcionaban únicamente para el cuidado de los enfermos: más allá de albergar a los pobres en sus instalaciones y darles comida, cama y ropa, se pretendía realizar un proceso de transformación del alma ${ }^{16}$ a través de campañas de catequismo, misiones a los pueblos vecinos y retiros espirituales.

15 Castro, Caridad y beneficencia, 131.

16 La transformación del alma era un proceso que beneficiaba tanto a los miembros de las sociedades como a los pobres y beneficiados de las labores de caridad. Por eso, al tratar el tema de la caridad no se debe olvidar que las elites se beneficiaban al igual que las personas a las que ayudaban: conseguían cumplir con un deber religioso, lograban indulgencias y asumían una posición privilegiada en la sociedad. 
Las labores de catequización eran realizadas por hombres y mujeres, en diferentes espacios, tales como la penitenciaría, los hospitales y las parroquias. Las sociedades del Sagrado Corazón e Hijas de María fueron las más activas en este campo, realizando retiros espirituales para las esposas de los artesanos, las sirvientas y las señoritas.

Resulta relevante rescatar una de las características más significativas del trabajo de las sociedades católicas de la época: los voluntarios se acercaban realmente al pobre, estableciendo relaciones cercanas de padrinazgo y afecto. No se trataba simplemente de asistirlos en los asilos u hospitales, pues sociedades como la de San Vicente realizaba visitas domiciliarias con el fin de conocer de cerca las necesidades de sus beneficiarios, además de identificar el progreso de las familias, a partir de las ayudas recibidas. ${ }^{17}$

Además, esta relación directa con los pobres se interpretó, hasta cierto punto, como una evidencia de que el catolicismo había abandonado su actitud defensiva y había eliminado las distancias con la población. ${ }^{18}$ Esto permitió a las sociedades infiltrarse en los diferentes sectores de la sociedad, para desde allí legitimar su labor y conseguir adeptos para sus proyectos.

17 Debe entenderse que las visitas domiciliarias no tenían como único objetivo acercarse pasivamente a la población, era un mecanismo de control según el cual la familia beneficiaria tenía que demostrar que era moral y cristianamente correcta para así poder seguir recibiendo las ayudas. Castro, "Inicios de La asistencia social en Colombia”, en: Revista CS, n. ${ }^{\circ} 1$ (2007): 163.

18 Loaiza, Sociabilidad, religión y política, 286. 
Uno de los sectores que recibió mayor atención por parte de las sociedades fue el artesanado. El trabajo de las sociedades católicas de elite con los artesanos se basó en potenciar las asociaciones de ayuda mutua, abrirles espacio en las celebraciones religiosas (para que participaran activamente y realizarán trabajos manuales), promocionar sus productos y crear escuelas de trabajo manual. ${ }^{19}$

El acercamiento a los sectores artesanales funcionó bajo dos lógicas: la primera, era necesario acercarse a un sector políticamente activo y fuerte con una gran influencia en la ciudad; y la segunda, era menester promover la industria nacional como un elemento fundamental para lograr el progreso y civilización del país.

\section{La instrucción}

En una primera instancia la caridad estaba dirigida únicamente a la población pobre, ${ }^{20}$ lo que reduciría su impacto a un grupo limitado de personas. No obstante, la caridad también era entendía como un medio para logar el progreso social y moral de todo el país, por lo que, en el marco de las acciones caritativas, se impulsó un proceso educativo para toda la población fuera esta pobre o no.

19 Gilberto Loaiza y David Sowell describen cómo después del golpe de Melo en 1854 las elites liberales se alejan del artesanado dejándole el campo libre a las sociedades católicas y el clero, quienes llegarían a ofrecer plena protección y ayuda a un artesanado en crisis económica. Loaiza, Sociabilidad, religión y política, 236; y Sowell, Artesanos y política en Bogotá.

20 Entendiendo por esta un grupo de personas que carecen de lo necesario para vivir. 
En este sentido, la instrucción constituyó un elemento fundamental en la apuesta caritativa, moralizadora y "modernizadora”, por cuanto permitía tanto la vinculación laboral de la población a través de la educación técnica como el avance moral por medio de las enseñanzas cristianas. Por ese motivo, el proceso de instrucción desarrollado por las sociedades incluyó a artesanos, mujeres, niños y niñas de diversos sectores sociales.

Las sociedades que más se preocuparon por la creación de escuelas y espacios de aprendizaje religioso mediante programas de catequización en las iglesias fueron la sociedad de San Vicente de Paúl y la sociedad del Sagrado Corazón de Jesús. Ya en 1878 Bogotá tenía treinta y siete escuelas primarias y solo seis eran gratuitas, cuatro a cargo de las Hermanas de la Caridad y dos a cargo de la sociedad de San Vicente. ${ }^{21}$ Esta última sociedad abrió escuelas gratuitas en seis barrios de la ciudad: Las Cruces, Las Nieves, Santa Bárbara, La Catedral, San Victorino y Santa Isabel; y desarrolló programas misioneros en las poblaciones rurales cercanas.

La sociedad de San Vicente de Paúl fue pionera en la creación de escuelas de artes y oficios para los pobres. La primera escuela fue fundada en $1877^{22}$ y estaba dirigida a los artesanos y obreros. Con esto se pretendía impulsar la industria y el trabajo en el sector artesanal.

Por otra parte, los espacios de formación religiosa creados por la Sociedad del Sagrado Corazón de Jesús fueron

\footnotetext{
21 Castro, Caridad y beneficencia, 144.

22 Castro, Caridad y beneficencia, 146.
} 
principalmente para niñas abandonadas y de bajos recursos. Contaban con cursos de historia sagrada, religión, historia patria, gramática y lectura. Paralelamente a esto se crearon las clases de catequismo, todos los sábados en la catedral primada, con el fin de formar a los niños, jóvenes y recién casados en sus obligaciones religiosas. Este trabajo giró en torno a la necesidad de promover la costumbre de las primeras comuniones, así como de incitar el matrimonio católico y los bautizos en toda la población.

El proyecto educativo estuvo acompañado de la publicación de periódicos y libros, cuya difusión no fue únicamente para las elites. La prensa se pensó como un espacio para la difusión de conocimiento útil, que ayudara a enriquecer a los pobres. Los redactores de los periódicos afirmaban que escribían para "las clases menesterosas de nuestra sociedad, para aquellos privados de la instrucción, para ambos sexos". ${ }^{23}$ Eran publicaciones abiertas a todo el público, trataban los temas de instrucción moral, literatura cristiana, noticias de los adelantos científicos y artísticos, así como el avance de las labores caritativas. Los voluntarios de las sociedades procuraban leer la prensa católica en los colegios, las cárceles, los hospitales y asilos, utilizándola como una herramienta educativa.

Junto a los establecimientos creados para los sectores bajos y artesanos, se plantearon instituciones educativas católicas para los hijos de las elites, varias de las cuales estuvieron coordinadas por miembros de sociedades católicas. Estas

23 La Caridad, 1864. "Prospecto", 24 de septiembre. 
escuelas buscaban una educación más avanzada, e incluían clases de instrucción religiosa, latín, francés, inglés, alemán, música, dibujo lineal, matemáticas, filosofía intelectual, literatura histórica, nociones elementales de agricultura, minería, química, geología, botánica, zoología, jurisprudencia, derecho canónico, teología, historia sagrada y eclesiástica. ${ }^{24}$ Asimismo, incluyeron otros espacios de formación para los miembros, amigos y familiares de sociedades católicas, tales como tertulias literarias, compra de libros y establecimiento de bibliotecas.

Debemos resaltar que la política instruccionista de las sociedades católicas tenía dos grandes finalidades: civilizar al pueblo para que se acogiera a los cánones del buen ciudadano, comportándose como un individuo moralmente correcto, con miras al progreso y la civilización; y hacer contrapeso a las políticas educativas laicas del Estado liberal que pretendían desplazar a la religión de las escuelas.

\section{Bazar de los pobres}

Las sociedades utilizaron diferentes mecanismos de autosostenimiento, dependiendo de sus necesidades financieras. La Juventud Católica, por ejemplo, al no tener que costear directamente ningún establecimiento en particular, basaba sus contribuciones en las donaciones y cuotas de sus afiliados; mientras que la sociedad del Sagrado Corazón, con más obligaciones, realizaba rifas semestrales y recibía donativos de diferente índole.

24 El Tradicionista, 1871. "El colegio de San Vicente”, 26 de diciembre. 
Pero las donaciones y las actividades en pro de conseguir fondos no eran suficientes. La inestabilidad económica de las sociedades católicas representaba serios inconvenientes para el desarrollo de obras de caridad de largo alcance: la atención de los hospitales, la regularidad de los retiros espirituales, incluso la solemnidad de las celebraciones religiosas se vieron coartadas en muchas ocasiones por la falta de recursos. Aun así, la labor caritativa y benéfica de la población bogotana mantuvo con vida a estas sociedades brindándoles los recursos necesarios: la recolección para el jubileo del Papa, la construcción de la parroquia de Nuestra Señora de Lourdes, la donación de ropa para los hospitales y el voluntariado de muchas mujeres y hombres facilitaron los recursos económicos de estas organizaciones.

Una de las labores de recolección de fondos de mayor alcance fue el bazar de los pobres, un acto anual que duraba entre dos y ocho días, dependiendo de los objetos de recaudación y las necesidades a cubrir. Este evento contaba con la participación masiva de la población bogotana.

El bazar estaba instituido en el reglamento de la sociedad de San Vicente de Paúl, con el objetivo de recaudar fondos para el funcionamiento del hospital, de los asilos y de las demás obras de caridad desarrolladas por la sociedad, al tiempo que pretendía estimular el progreso de la industria y las bellas artes con la promoción y venta de objetos realizados por los artesanos. ${ }^{25}$

25 Reglamento de la Sociedad de S. Vicente de Paúl de Santafé de Bogotá (Bogotá: Imprenta a Cargo de la F. Mantilla, 1886) BLAA. 
Se convocaba a colegios, escuelas, artesanos de diferentes oficios, empleados públicos, maestros, señoritas, y otras personas para que donaran y compraran objetos, y así contribuir a las obras de caridad de la sociedad. El bazar logró una gran popularidad que le permitió perdurar durante varios años. ${ }^{26}$ Incluso durante períodos de guerra o inestabilidad política, el bazar, realizado a puerta cerrada, lograba conseguir los fondos necesarios para la sociedad.

El evento funcionó desde 1865 cada 20 de julio (después pasará a realizarse en las primeras semanas de agosto, puesto que celebrar el bazar el mismo día que de las fiestas patrias traería diversos inconvenientes) y se realizaba en los comercios de diferentes miembros de la sociedad de San Vicente; contaba con una junta para su funcionamiento y con comisiones encargadas de promocionar el evento. La participación en esta actividad era una labor relevante para los integrantes de la Sociedad de San Vicente y el ser presidente de la junta directiva del evento era un reconocimiento público a la labor realizada en otras obras de caridad. Por este cargo pasaron personajes como Manuel María Pardo, Justino Va-

26 El bazar logro tal popularidad que era costumbre, $\mathrm{y}$ símbolo de prestigio para las señoritas llevar una joya de segunda comprada en el bazar, como símbolo de caridad. "[...] i ese día se presentó, por primera vez también, el hermoso espectáculo que exhibían las más bellas señoritas de Bogotá, vagando de mesa en mesa con brillantes mariposas, escogiendo, mirando i dando ruborosas lo que llevaban en sus portamonedas para socorrer a los pobres, sin mostrar que daban una limosna. Embellecida aún más por ese púdico sentimiento de la caridad que no deja percibir a la mano izquierda lo que da la derecha, fijaban las tiernas miradas de los jóvenes que las contemplaban con admiración”. El Iris, 1866. "El iris", 2 de septiembre. 
lenzuela y José Javier Ortiz, todos ellos importantes figuras de las sociedades católicas de la época.

El bazar constituyó una de las labores más importantes para la sociedad, puesto que de él provenían casi el $80 \%$ de los ingresos, siendo así fundamental para el desarrollo de las labores de caridad. ${ }^{27}$ Un ejemplo claro del alcance económico del bazar es la construcción de la iglesia de Lourdes en Chapinero, a las afueras de la ciudad, financiada con las ganancias obtenidas en este evento.

En 1866, debido al aumento de los gastos para el sostenimiento de las obras de beneficencia, se decidió crear una comisión de miembros encargada únicamente del bazar y otra comisión de señoras para su organización. El grupo de mujeres del bazar realizaba la propaganda en los colegios de mujeres, en los asilos y en las demás sociedades católicas femeninas; su labor fue altamente reconocida, ya que ellas fueron las mayores contribuyentes económicas de esta obra. Entre las mujeres que estuvieron a cargo están la señora Sotera Lorenzana de Mejía, Joaquina Cordovez, Bárbara Álvarez de Obregón y Carolina Elvers de Pizano, todas ellas integrantes de otras sociedades católicas.

Si bien el bazar era realizado por la sociedad de San Vicente, convocaba a todas las sociedades católicas de Bogotá. Así pues, el bazar era un espacio de encuentro de diferentes sectores en el que los artesanos exponían sus productos, las elites demostraban su caridad y las sociedades exponían su obra.

27 Castro, Caridad y beneficencia, 297-300. 
El evento contó con gran participación de la población bogotana y permitió un espacio de encuentro idóneo entre los miembros de las sociedades y otros sectores, en especial artesanos, que eran invitados con gran insistencia para que vendieran sus productos, además de organizar cierta parte del bazar. Su participación en este evento era fundamental, pues eran ellos los encargados de mostrar los avances de la industria y aprovechar este espacio como una oportunidad de crecimiento económico.

\section{El buen pobre}

Es importante resaltar que las labores realizadas por las sociedades católicas no estaban pensadas para solucionar los problemas de pobreza del país, sino para tratar de contener el conflicto social que se incrementaba diariamente. Por eso, más allá de ayudar a las personas a superar sus condiciones de pobreza, las organizaciones se proponía transformar a estas personas en "pobres decentes".

Para entender este punto debemos partir del hecho de que la pobreza se entendía como un problema económico y una consecuencia de los vicios y la falta de moral de la población:

Es verdad que los pobres merecen la compasión y el apoyo de sus hermanos en sociedad: pero también es verdad que no dejan de merecer su suerte, por la inercia y vagabundería en que han vivido, alejados del trabajo y embruteciendo 
en la ociosidad del alma y el cuerpo que Dios les dió para que se hiciesen útiles á sí mismos y a los demás. ${ }^{28}$

En este sentido, para atender la pobreza se requería una transformación plena del pobre, ofreciéndole, además de estabilidad económica, un alma buena y cristiana. Así, el "buen pobre" fue definido a partir de pautas de comportamiento: este debía sentirse avergonzado de su situación, procurar trabajar y mejorar, pero no tratar de cambiar su posición en la sociedad; debía estar aseado y no demostrar sus necesidades. Sin excusa debería asistir a misa, ser buen cristiano, hacer caridad con lo poco que tuviera y ser buen ciudadano. ${ }^{29}$

Una forma de entender esta dinámica es examinando la clasificación de los pobres que hace San Vicente. La sociedad prevé un orden de prioridades para repartir sus ayudas: en primer lugar estaban las madres de familias enfermas, sin ningún tipo de ayuda; seguidas de las inocentes huérfanas; luego los artesanos honrados sin posibilidad de trabajar; y finalmente las personas a quienes dar trabajo. ${ }^{30}$ Esta clasificación mezclaba valores morales con necesidades físicas, y agregaba instrucciones específicas de acción para cada caso (una familia que pudiera trabajar pero que no tuviera empleo era ayudada a conseguir trabajo, pero no se le brindaba asistencia económica), haciendo énfasis en que el objetivo de la sociedad era ayudar a aquellos que eran "realmente necesitados".

28 El Mosaico, 1871. "Mucha caridad”, 2 de julio.

29 La Caridad, 1873. "Malos diarios”, 6 de marzo.

30 Reglamento de la Sociedad de S. Vicente de Paúl de Santafé de Bogotá. (Bogotá: Imprenta a Cargo de la F. Mantilla, 1886), BLAA. 
Dicha lista de prioridades no respondía únicamente a las necesidades materiales de los pobres, pretendía además determinar quién "merecía” su ayuda. En un artículo de 1866 publicado en La Caridad, ${ }^{31}$ la Sociedad de San Vicente responde a una serie de acusaciones en contra suya aclarando que todas las labores de caridad son gratuitas para los beneficiarios, y que la única carta de presentación que necesitan es ser pobres, sin importar el partido político del cual provengan, reservándose para sí la potestad de determinar quiénes son los pobres vergonzantes y cómo se les ayuda, al fin y al cabo no puede ayudarlos a todos y mucho menos a los “viciosos e inmorales”. Determinar quién merece y quién no merece ser beneficiario de las labores de caridad será una decisión medida por ideas frente a quién es moralmente correcto, un buen católico y un ciudadano ejemplar.

Por último, debemos mencionar que el ideal del buen pobre, basado en las nociones de trabajo, educación, ahorro, familia e higiene, condicionó la asistencia social desarrollada por la elite en general. ${ }^{32}$ Con esto queremos resaltar que si bien la preocupación moral-cristiana era propia de la actividad caritativa desarrollada por la Iglesia y las asociaciones laicas católicas, las preocupaciones en torno a la vagancia, la suciedad y los vicios concernían a toda la elite, por lo que no podemos pensar en este ideal como una apuesta desarrollada únicamente por los católicos ultramontanos.

31 La Caridad, 1866. “Clasificación de los pobres”, 22 de junio.

32 Castro, Caridad y beneficencia, 88-89. 